\title{
Australia's Middle Power Approach Towards Climate Change in Pacific Island
}

\author{
Siti Dinda Narisya ${ }^{1}$
}

UIN Syarif Hidayatullah Jakarta

\begin{abstract}
This article tends to examine the ways Australia approaching climate change in the region associated with its middle power status. Pacific Islands or Southwest Pacific Region is a regional territory that almost of all its surface covered by water. The region is prominent for having numbers of island countries or island states which are very dependent on natural conditions. They are vulnerable to the change of nature thus it hits their top national security. The issue of climate change in recent years has gotten more serious attention from all over the world and so does the pacific island region with no exception. Australia with its unique feature of being known as a middle power state and as the most secure nation in the region has served a distinctive approach on addressing the issue of climate change. The behavior and identity approach are adequately in line to establish certain strategies associated with middle power status in the role of guiding Australia's foreign policy.
\end{abstract}

Keywords: climate change, Island states, middle power, Australia, foreign policy.

\section{INTRODUCTION}

The southwest pacific region is prominent of having numbers of island states and therefore this region also called Pacific Islands Region. To be precise many of them classified as small island developing states (SIDS) by the United Nations while they as well called Pacific Island Countries (PICs). SIDS are a distinct group of developing countries facing specific social, economic and environmental vulnerabilities (UN-OHRLLS, n.d.). In the southwest pacific, the group of PICs and also SIDS are Fiji, Kiribati, Nauru, Papua New Guinea, Samoa, the Solomon Islands, Tonga, Vanuatu and Tuvalu (Howes et al., 2018).

Their existence challenged by the emerging issue of climate change. Their geographical situation is very vulnerable to the changing nature of the sea. The rapid climate change which contributes to the sea level rise is not an anticipated fact, it is happening right at the moment. It is a real concern they are facing right now and it becomes their top national security (Howes et al., 2018).

Like what has already mentioned, the island states are mostly developing countries and their size are small. Even prior to the climate issue which is now threatening their existence, in general PICs find it hard to face the primary national security matters. Climate change threat will only be able to overcome if all parties willing to participate. 
The reason is not only because of PICs capability backgrounds that is considered to be quite not capable of facing the challenges given by climate change. The issue indeed a global phenomenon and thus to tackle it, countries are eligible to work together. As for the case in the pacific islands' region, the PICs can unite and start working together in tackling the issue and the impact of climate change but it is not enough.

The matter of power in the region cannot be excluded from this issue. Climate change needs global responsibility to mitigate the upcoming risks. Australia with respect to its national power compares to the rest of the countries in the south pacific, solely attracts attention towards its action on this issue. Australia and the Pacific Island states have been known to have a long dynamic trail of how each foreign policy affects each other and how this affects the regional system. There are three ideas of the relations build between the pacific islands and Australia, which are as a threat, an opportunity, and a special responsibility.

This getting more interesting to look at Australia's existence which take into consideration of being the middle power in the system of international world. The term middle power is increasingly enter into discussion by Australian foreign minister, Gareth Evans when he is in office (Evans, 2007). The term was then self-proclaimed by Australian as a kind of the national identity.

Up until now there is still space to argue the definition and the concept of middle power states. However, there is one definition being most agreed by the international relations experts. Middle powers are states that are neither great nor small in terms of international power, capacity and influence, and demonstrate a propensity to promote cohesion and stability in the world system (Jordaan, 2003). The aim of this article is to see how the middle power status that Australia bears take place on addressing the issue of climate change and response to it in the south pacific region.

\section{ANALYTICAL FRAMEWORK}

This research is based on the concept of climate change as a threat to not only nature life but to human's life as a whole. Climate change is understood to be one issue of national security. It started to enter the discussion of international relations or social-political realms in 1970 (Steans, Pettiford, Dies, \& El-Anis, 2010). The social and political sides are actually going hand in hand with the change of the environment. It can be seen through how the industrial revolutionary is undermining the nature. The earth itself is the cost of industrial 
revolutions. The cost and benefit of global social-cultural innovations outcomes to the rest of the nature world which then allows the green politic theory a room to get more discussion.

The point of green politic theory is how the anthropocentrism has serious consequences on the balance of the nature that we often neglect. We often sacrificing nature life for the sake of what we called social and political welfare. Whereas the changing of the nature of planet earth is a serious thing that impacting many areas of people's life and if we continue neglecting it, the impacts will get worse. Entities that are close to nature are the one who are vulnerable to climate change such as states in pacific islands.

By realizing the fact, it can help the rest of the world to prepare and start taking serious action in tackling the issue of climate change. It asks the world to open their eyes to see that on the other side of the world which are having little advantages of the industrial revolution, but at the same time they are the ones who are at the front to bear its side effects. This also to reconfirm actions from the international actors, especially the ones who are geographically close to the state affected, as a responsibility of the neighboring state, like Australia to the pacific islands.

Climate change is the global common issue in which there are no states with exceptional conditions could escape from it, even of what we think the safest state. Australia with respect to its geographical providence that close to the island states has a quiet major role in giving responses to the issue of climate change. It creates a unique condition or identity of Australia which the world considers it to be the most powerful state in the region but for some cases it lacks the power of enforcement as superpower did.

It is one of the key features to look at how such trait affects their foreign policy towards contemporary issue such as climate change that is severely threatened island countries. Nevertheless, the term middle power is known to be a bit of ambiguity or somehow hard to define. But in a broader context middle power is a state with both the ambition and the capacity, to exercise significant influence in a specific but limited, arena of international relations (Chia, 1998).

In order to examine Australia approach on addressing climate change with its middle power status, at the very least, there are three lenses that can be used in order to acknowledge the background of its foreign policy which are the position approach, behavioral approach, and identity approach (Carr, 2014). The three are correlated, but the position approach particularly for Australia is proven to be a bit of almost no value in predicting or explaining 
the behavior of those states classed as middle powers that it might blurs what we can count for what we want to know (Evans, 2007).

The term middle power also reckoned of being one of many factors that shapes Australia foreign policy and it is called middle power diplomacy. This approach is to see how the middle power diplomacy as an embodiment of identity guides Australia's foreign policy to the world in general, to the region in specific. Especially on addressing the issue of climate change, it helps us discover Australia role on addressing the issue with their recognition of being middle power that then shapes certain role for Australia towards the region.

\section{Literature Review}

Climate change is one big term that used in global context to cover numbers of environmental issues caused predominantly by human activities. In one book titled International Security Studies, authors put the broad issue of climate change into a more international study context. It is considered to be in the discussion of what so-called environmental security. Environmental security itself covers a more purview of security issues such as state and human securitization as in the theory, whilst national and intergovernmental environmental securitization as parts of the discussion in practical case (Hough, Malik, Moran, \& Pilbeam, 2015).

According to the book, climate change is considered to be a non-traditional security issue, but as we dig deeper, we can probably say that its impacts are as vital as the traditional one. It is often called as a "threat multiplier" (Macpherson, 2017). One possible scenario is that climate change could affect security in the South Pacific region by weakening the capacity of governments to maintain security capabilities, and through the potential impacts of migration (Macpherson, 2017). Another transnational issue that would probably come into the surface was one caused by food scarcity that happened because of the change of climate which affecting the agricultural cycle. The unusual cycle might affect agricultural production. The food scarcity may lead to a big war and thus need to be anticipated at the very beginning.

The pacific islands are now facing several impacts ranged from social-economy problems to natural hazards which they have to be ready for anytime natural disasters hit their lands. There are numbers of environmental or natural situations they need to face such as the increasing of droughts and water scarcity, pollution and overuse of natural resources, overpopulation, coastal flooding, erosion, the change of weather cycle that affect the ecosystems and food chain, and it also affects human health (Mcleod et al., 2019). These 
facts also what makes pacific island undoubtedly the leading agent of climate action. They do it by combining their own systems of knowledge with the science to implement locally relevant and achievable climate solutions (Mcleod et al., 2019).

Australia is one big entity in the south pacific region with its middle power status in the global and also a dominant agent in the region (Schultz, 2014). Its presence in the region on addressing the issue of climate change is as crucial and important, as its activism trait brought in the scheme of middle power status. What is mentioned as the realizations of activism is also can be understood of standing as an advocate. It is willing to solve international problems when small powers are incapable of addressing them; particularly on low-political issues beyond great powers' interest (Hidayatullah, 2017). Nevertheless, The term middle power alone has been controversial as it considered to be a tautology (Carr, 2014). To put it in the case of Australia and international relations is also kind of challenging. Australia in this term is able to force policy but is not very powerful as many may argue. which is also safe to say that middle power apply the role of advocators, meaning they have prominent soft powers capability which actively launch branded foreign policy on low political issues, and play ad hoc coalitions in multilateral forums (Hidayatullah, 2017). The definition is suitable for Australia, especially in this case of climate change which is true is categorized in the low political issue of international relations subjects. Moreover, the point of soft power being stated before is understood to be a kind of ability to reach certain goal by influencing the choices of other parties using agenda setting, persuasion, and attraction (Hidayatullah, 2017) which again justify Australia middle power ways on reaching its foreign policy.

The advocate label can be illustrated in a simpler fashion as it is used in the legal field. It does not have power as powerful as the judge in the tribunal. But the advocates have an ability to help their clients (re: small powers) exercising their interest through the soft power specialty. They are forceful to bring the issue into the surface and to influence other parties to acknowledge the issue, but the final result is not on their hand. That is to say that they do not have much power as others who are categorized great powers but the existence of middle powers is not less important. Their presence is significant in bridging the interest of the small powers, big powers and also their own interest.

One questionable feature of being claimed as middle power is aside of being the supporting role for numbers of international world consensus, the foreign middle power activism it holds can also directly oppose the interest of the pacific island as a cost of not 
being the great ones who may enforce certain action to all parties. This reinforced by the fact that Australia has always reflected some balance between protecting or advancing national interests and a commitment to helping those who are in need (Elliott, 2011). In one report there was a declining number of climate aid and adaptation support in the region in 2011 because of Australia's drastic movement to reduce its supports whilst it is the single largest provider for this case (Betzold, 2016). This informs us that Australia and the pacific islands do not have a good enough relationship as what neighboring countries might have yet it is not likewise negative.

\section{RESULT AND DISCUSSION}

Many see Australia and pacific islands region relations unique and dynamics. Australia alone is already had a unique character with its European ancestry and its geographical bind which closer to Asia. This creates certain characteristic of how Australia combines the two when it behaves in the international system. Meanwhile, the south pacific is viewed by Australia as natural sphere of influence (Brown \& Army, 2012). By this far, Australia and the pacific leading manner of building relations are based on the development assistance scheme given by Australia to the pacific while there are still other different schemes of cooperation.

According to material capability, Australia is the major aid donor to the pacific islands region, both in a scheme of multilateral or bilateral relations (Henningham, n.d.). It even said by a political scientist, Richard Mulgan that the relationships are invariably one form of inequality that the economic gap between the two is the central fact of their mutual relations (Chia, 1998). It is also called an asymmetric relationship because of Australia predominance in almost all sovereign state attributions while many members of the island states are highly reliant upon foreign aid.

Looking through materialistic lens, the pacific islands with all due respect are identified being far below Australia, but their existence are increasingly gain more attention from Australia and other countries, as is for them to be sovereign states that cannot be ignored (Schultz, 2014). Australia in particular try to maintain the system that is now established which give them the convenience to move by assuring the pacific islands that Australia is the only 'helper' for them. It tries to limit external participations and still being the great power in the region.

Of all numbers of concerns in the region, climate change is one that evidently attract both entities to take serious role and actions. Despite of Australia's capability plus its large 
land mass which relatively in a better condition compare to island states, it cannot escape the threat of climate change. Together with pacific islands and international agent, Australia passes out some measures on climate change. Moreover, the climate change might threaten the stability of political climate in the region (Macpherson, 2017).

\section{The Role of Pacific Islands and Australia on addressing climate change.}

Its renowned stance of being in the front line of climate movements or activisms, the group of SIDS in the southwest pacific do have some measures to face their national security agenda of protecting nature. It will not greatly help the situation to do it unilaterally, so the region often work in cooperation. Australia is one leading partner on this issue apart from international collective movements owned by the United Nations (UN). The main focus of every action and movement in regards with foreign policy are primarily work in a framework of climate adaptation.

One of the most popular international commitment on climate change is the 1992 United Nations Framework on Climate Change (UNFCCC) and the 1997 Kyoto Protocol which was the following event of the UNFCCC in which Australia is one of the participants. By committed to the treaty, Australia is taking climate responsibilities into higher level. It committed to cut the greenhouse gas emissions, to act accordance with the principle of common (but differentiated) responsibilities, to provide technological and financial support to developing countries and to acknowledge and respond to the needs of developing countries (which PICs are included) (Elliott, 2011).

By looking through the middle power approach, this considered to be the realization of the renowned middle power diplomacy. Like any other multilateral cooperation, the Kyoto Protocol is a reflection of how Australia approaching a wider network. It is an act of balancing between protecting national interests and also a commitment of taking responsibility to vulnerable countries. What kind of national interest? The interest of joining a global initiative is to maintaining and reinforcing access to the greater power within the multilateral institutional arrangements with some degree of expectation that will make them act in a fashion that is beneficial to Australia.

In the same time it also meant to provide more opportunities for a role that enables Australia to be more independent of its more powerful allies (Chia, n.d.). The definition is constructed by combining the two political hues interest, the labor party and the conservative. Not only that, it is also the interest of building stronger relations with the PICs of trying to carry forward the predicament of climate change which they need to overcome. 
This theme, however, shows that Australia tries to draw sympathy which it views as a guarantee of PICs loyalty to Australia.

This international participation in the middle power discourse means that Australia is taking middle power diplomacy and international activism. Middle power diplomacy is the adoption of an internationalist perspective and policy that means actively participating in multilateral forums, leading in specific niche areas and acting as a bridge among nations (Lee, Chun, Suh, \& Thomsen, 2015). Although it was not a direct action toward pacific islands, it approves the middle power ways on adapting certain issues which in this case climate change.

Another way Australia used on approaching the PICs regarding climate change issue is through a collective movement based on regional cooperation. It is still based on middle power diplomacy but aside from maintaining support from great powers it is Australia approach to countries that are "smaller" than it. It is an act or behavior of Australia to declare that it is the only helper and the generous neighbor of PICs which mean both of them should maintain the good relationship that already exist. The relationship which only is Australia being the PICs top great partner has recently haunted by the recent situation of China emerging existence in the region. What makes the PICs essential for Australia? It is also because of the trend of growing interdependence among state and non-state actors, so any entities anywhere around the world is facing mutual partnership although not all of them is the top priority.

Pacific Island Forum is one example. In this forum we could assess Australia's restraint in the region by having the status middle power. Although the forum might permits some degree of Australia national interests, but as a supra-national body, the forum reinforces the legitimacy of even the smallest and weakest of island states in which provides a constraining framework on any countries involvement or influence in regional affairs (Henningham, n.d.). Not only the limitations that confirmed middle power status, in the region the responsibility Australia bear is also a completion of its role and status. Several PICs are taking more assertive manner in their government system. This assertiveness trailed into foreign affairs which will not let Australia move arbitrarily.

\section{Australia and its unilateral action}

Aside from multilateralism being one theme of the embodiments of middle power diplomacy, Australia is also executing their middle status unilaterally by constantly allocating fund toward PICs. This can be seen through several programs that Australia pass out within the framework of its government which called Pacific Regional Program ("Overview of 
Australia's Pacific Regional aid program," n.d.). It said that in 2019-2020 the program is that Australia will provide an estimated A\$336.4 million in Official Development Assistance to the Pacific. It also managed an estimated $A \$ 231.5$ million in bilateral funding.

With this being delivered, the unilateral action is the manifestation of Australia soft power approach in low political issue which in this context is climate change. In 2009 through its government official document, it established a booklet titled "Engaging Our Pacific Neighbors on Climate Change: Australia's Approach." The establishment of such booklet alone gave us the impression that Australia is willing to take on serious path in terms of addressing climate change in the pacific. The booklet consists certain sets of Australian ways on responding the PICs with their concern of climate change threats. It is one form of middle power characterization on implementing the soft power ability.

There is one enticing subject in the booklet which is Australia scientific projects as an attempt to provide information about the changing nature of the sea. The project named South Pacific Sea Level and Climate Monitoring Project (SPSLCMP) (Commonwealth of Australia, 2009). This is one of the initiatives Australia tries to employ as its comparative advantage of knowledge and technology which is preferable in the region. The information and data that has been collected can help Pacific governments plan and prevent the impacts of climate change. The total funding for this program in over four phases from 1991 to 2010 is A \$32 million.

\section{Recent Developments}

Despite Australia efforts to serve and play the best in the region, through unilateral or multilateral ways, challenges still are not escapable. In recent years, Australia progressive actions on climate change instead considered to be declining in the region (O'Gorman, 2019). More facts to be include that Australia's aid budget has shrunk wherein it is falling from \$5.05bn in 2013 to \$4.04bn in 2019 financial year (Doherty, 2019). Wherein Australia is the world's worst per capita polluters and the biggest exporters of thermal coal but it is not showing actions as expected. This behavior again draws upset response from Pacific Islanders.

It is seen of becoming a mundane development and is not doing a powerful action, with that being said Australia might damage its stance in the region. By being middle power, Australia should have taking care of its neighbor more responsive, even more so in the projection of Asia Pacific political dominance shift to the east Asia. The Pacific Islanders have collective powers that probably could beat Australia long established strength. Indeed, 
they can deviate their partnership preference toward any party that is put more serious effort on climate change initiative. A few members of the pacifics have begun to shift its diplomatic relations to China which has promised the region of providing infrastructure funding amounts billions of dollars through its global Belt and Road Initiative (Doherty, 2019).

Australia through its International Development Minister, Alex Hawke has given statement in response to the situation of power transition in the region. Hawke claimed that the willing to allocate $\mathrm{A} \$ 500 \mathrm{M}$ which also counts to be the largest ever committed to climate change measures in the pacific is cannot be acceptable to say that Australia has not done enough. But it might be true that apart of the funding, the sets of climate actions programs had not obtained the same expected result as in previous years. Hawke said that Australia is now trying to find new ways to climate issue as in try to find new aid plans for it to be recast in responding the conditions of changing global order (Doherty, 2019).

\section{CONCLUSION}

The middle power status Australia own is a unique trait although it is quite hard to define and despise the ambiguity. It has quite many ways to define the status. It gives Australia certain opportunities to achieve their national interest yet at the same time it put some hurdles on the dilemmatic situation between the greater powers and the smaller ones.

On the issue of climate change Australia apply its identity of being middle power by issuing some actions that is going to protect and give them security in the Pacific Islands region. In general, those actions have to matched their interest and beneficial for them. It ranged from the unilateral ways to the multilateral ones.

On its way, Australia is not taking their concern of the region climate crisis into a higher account. Nevertheless, Australia being the biggest in the region does not mean it will not have disagreement with the rest pacific islanders. Australia should be pay more attention to its neighbors and so it can save the political stability in the region which at the end will also be beneficial for Australia. 


\section{REFERENCES}

Brown, C. P., \& Army, B. (2012). Australian Influence in the South Pacific. 189(December), 6678.

Carr, A. (2014). Australian Journal of International Is Australia a middle power? A systemic impact approach Is Australia a middle power? A systemic impact approaches. (November), 37-41. https://doi.org/10.1080/10357718.2013.840264

Chia, E. K. W. (n.d.). Middle Powers In The Modern State System: A Case Study of Australia's Role As A Regional Actor.

Chia, E. K. W. (1998). Middle Powers In The Modern State System: A Case Study of Australia's Role As A Regional Actor.

Commonwealth of Australia. (2009). Engaging our Pacific Neighbours on Climate Change: Australia's approach. Department of Climate Change.

Doherty, B. (2019, November 19). Australia's overseas aid set for shake-up as Pacific power balance shifts. The Guardian. Retrieved from https://www.theguardian.com/australia-news/2019/nov/19/australias-overseasaid-set-for-shake-up-as-pacific-power-balance-shifts

Elliott, L. (2011). Australia, Climate Change and the Global South. 100(415), 441-457. https://doi.org/10.1080/00358533.2011.595261

Evans, G. (2007). The "Middle Power" Concept in Australian Foreign Policy. 53(4), 538-551.

Henningham, S. (n.d.). No Easy Answers: Australia and the Pacific Islands Region.

Hidayatullah, N. L. (2017). Classifying Middle Powers based on their Regional and Multilateral Roles: Differentiating Middle power Enforces, Assemblers, and Advocators. 143(UICoSP), 113-117. Atlantis Press.

Howes, E. L., Birchenough, S., Lincoln, S., \& Environment, C. (2018). Effects of Climate Change Relevant to the Pacific Islands. 1-19.

Jordaan, E. (2003). The Concept of a Middle Power in International Relations: Distinguishing between Emerging and Traditional Middle Powers The concept of a middle power in international relations: 30, 165-181. https://doi.org/10.1080/0258934032000147282

Lee, S., Chun, C., Suh, H., \& Thomsen, P. (2015). Middle Power in Action: The Evolving Nature of Diplomacy in the Age of Multilateralism.

Macpherson, G. (2017). Regional security implications of climate change and natural disasters in the South Pacific. 257-268.

O'Gorman, D. (2019). Australia's standing in Pacific has plummeted because of our climate change failure. Retrieved from The Guardian website: https://www.theguardian.com/environment/commentisfree/2019/jun/08/australi as-standing-in-pacific-has-plummeted-because-of-our-climate-change-failure

Overview of Australia's Pacific Regional aid program. (n.d.). Retrieved from Australia Government: Department of Foreign Affairs and Trade. website: https://www.dfat.gov.au/GEO/PACIFIC/DEVELOPMENTASSISTANCE/Pages/development-assistance-in-the-pacific 
Schultz, J. (2014). Theorizing Australia - Pacific Island relations Theorising Australia - Pacific Island relations. 7718 . https://doi.org/10.1080/10357718.2014.917271

Steans, J., Pettiford, L., Dies, T., \& El-Anis, I. (2010). An Introduction to International Relations Theory: Perspectives anad Themes. London: Pearson Education.

UN-OHRLLS. (n.d.). SMALL ISLAND DEVELOPING STATES: Small Islands Big(ger) Stakes. 